\author{
Nobuaki Shime \\ Graeme MacLaren
}

\section{Polymyxin B haemoperfusion in septic shock patients}

Accepted: 6 July 2015

Published online: 16 July 2015

(C) Springer-Verlag Berlin Heidelberg and ESICM 2015

\section{Dear Editor,}

The recent article by Payen et al. [1] evaluated the effects of polymyxin B haemoperfusion (PMX-HP) in patients with septic shock from peritonitis. The clinical efficacy of this theoretically attractive treatment has long been debated [2,3]. Although one earlier study suggested possible benefits through a reduction in mortality [2], some methodological flaws associated with the study design prevented definitive conclusions. In the multicentre randomized controlled study by Payen et al. [1], no significant clinical benefit with PMX-HP treatment was demonstrated. These results may diminish enthusiasm for this treatment. However, we believe that any such therapeutic nihilism may be premature or misguided for several reasons. First, only three-quarters of the patients had proven infection with Gram-negative organisms. Theoretically, PMX-HP acts by binding to lipopolysaccharides in the outer cell wall of Gram-negative organisms. This may restrict its effectiveness to only infections caused by these pathogens. Conducting a post hoc analysis differentiating patients with or without Gram-negative infections (especially bloodstream infection) might help clarify the real efficacy of PMX-HP treatment. Second, elucidating the reasons behind the increase in the haematological components of SOFA scores in the PMX-HP group is important. By exposing blood to contact with an artificial membrane, PMXHP treatment carries the inherent risk of exacerbating coagulation and inflammation disorders. Presenting coagulation parameters and making a statistical comparison between groups might be helpful. Finally, it is important to state the mechanisms of death in both groups to help clarify the reasons for the trend toward increased mortality in the PMX-HP group. Could it be due to an increase in coagulation disorders from PMX-HP? We believe these questions need to be considered prior to conducting more trials or attempting to apply this treatment clinically.

\section{Compliance with Ethical Standards}

Conflicts of interest The authors have no conflict of interest.

\section{References}

1. Payen DM, Guilhot J, Launey Y, Lukaszewicz AC, Kaaki M, Veber B, Pottecher J, Joannes-Boyau O, MartinLefevre L, Jabaudon M, Mimoz O, Coudroy R, Ferrandière M, Kipnis E, Vela C, Chevallier S, Mallat J, Robert R, ABDOMIX Group (2015) Early use of polymyxin $\mathrm{B}$ hemoperfusion in patients with septic shock due to peritonitis: a multicenter randomized control trial. Intensive Care Med 41:975-984. doi: $10.1007 / \mathrm{s} 00134-015-3751-\mathrm{z}$
2. Cruz DN, Antonelli M, Fumagalli R, Foltran F, Brienza N, Donati A, Malcangi V, Petrini F, Volta G, Bobbio Pallavicini FM, Rottoli F, Giunta F, Ronco C (2009) Early use of polymyxin $\mathrm{B}$ hemoperfusion in abdominal septic shock: the EUPHAS randomized controlled trial. JAMA 301:2445-2452

3. Vincent JL, Laterre PF, Cohen J, Burchardi H, Bruining H, Lerma FA, Wittebole X, De Backer D, Brett S, Marzo D, Nakamura H, John S (2005) A pilot-controlled study of a polymyxin B-immobilized hemoperfusion cartridge in patients with severe sepsis secondary to intra-abdominal infection. Shock 23:400-405

\section{N. Shime $(\bowtie)$}

Department of Emergency and Critical Care Medicine, National Hospital Organization Kyoto Medical Center, 1-1 Mukaihata-cho, Fukakusa, Fushimi-ku, Kyoto 612-8555, Japan e-mail: shime@koto.kpu-m.ac.jp

\section{G. MacLaren}

Cardiothoracic Intensive Care Unit, National University Hospital, 5 Lower Kent Ridge Rd, Singapore 119074, Singapore e-mail: gmaclaren@iinet.net.au 